\title{
Therapeutic effects of Iranian herbal extracts against Trichomonas vaginalis
}

\author{
Zohreh Fakhrieh Kashan ${ }^{1}$, Mahdi Delavari ${ }^{*}$, Mohsen Arbabi ${ }^{2}$ and Hossein Hooshyar ${ }^{2}$ \\ ${ }^{1}$ Department of Medical Parasitology, School of Public Health, Tehran University of Medical Sciences, Tehran, Iran; \\ ${ }^{2}$ Department of Medical Parasitology, School of Medicine, Kashan University of Medical Sciences, Kashan, Iran
}

Received 22 April 2017; revised 17 June 2017; accepted 25 June 2017

\begin{abstract}
Trichomonas vaginalis is a flagellated parasite affecting about 276 million people annually worldwide. Tricomoniasis is associated with different complications in pregnant women and infants. 5'-nitroimidazole derivatives (metronidazole, ornidazole, and tinidazole) are FDA approved drugs recommended for trichomoniasis treatment. Treatment with metronidazole 5'-nitroimidazole derivatives is associated with many side effects, and drug resistance to metronidazole has been reported in some cases. Recently, many attempts have been made to evaluate the effects of plants on causative agents of vaginal infections. In our research, the national and international databases were searched and the effects of various herbal extracts on $T$. vaginalis in Iran were reviewed from 2006 to 2016. In articles investigated, some plants had favorable antitrichomonal effects and needed to be further investigated. All the plant extracts have only been evaluated in vitro. Surveys of different articles in this review show that the active ingredients present in different parts of plants, including aerial parts, leaves, flowers, stems, and root can be suitable sources for introducing and developing new antitrichomonal compounds. DOI: 10.18869/acadpub.ibj.21.5.285
\end{abstract}

Keywords: Trichomonas vaginalis, Medicinal plants, Iran, Herbal, Extract

Corresponding Author: Mahdi Delavari

Department of Medical Parasitology and Mycology, Kashan University of Medical Sciences, Kashan, Iran; Tel. (+98-31) 55540021-25; Fax: (+98-31) 55541112; E-mail: mdelavari1@gmail.com

\section{INTRODUCTION}

$T$ richomonas vaginalis is a protozoan parasite and the causative agent of infection in human vagina, prostate gland, and urethra ${ }^{[1-3]}$. T. vaginalis is a parasite of the Trichomonadidae family and genus of Trichomonas. Morphologically, this parasite is pyriform and occasionally amoeboid form ${ }^{[3-}$ 6]. Prevalence of trichomoniasis is estimated about 276 million new cases annually worldwide and associated with different complications such as preterm birth, high mortality in infant, and low birth weight ${ }^{[7-9]}$. About $85 \%$ of infected women and $77 \%$ of infected men with this parasite are asymptomatic. In men, trichomoniasis can be associated with urethral discharge and dysuria. In general, among women, the common sites of infection are vagina, urethra, and endocervix, and clinical features include vaginal discharge (which is often diffuse, malodorous, and yellow-green), dysuria, itching, pruritis, vulvar irritation, and abdominal pain. Other complications could be infection of the adnexal, endometrium, and Skene's and Bartholin's glands. Trichomoniasis also may cause the increased risks of other sexually transmitted diseases; infection is associated with 1.52.7 times greater risks of HIV acquisition and transmission ${ }^{[10-13]}$. Trichomoniasis in women is more common at the age of 16-53. Infection is usually transmitted by sexual contact and restricted to the genital tract. Wet mount examination is the most common method of diagnosis, but $T$. vaginalis infection can also be diagnosed by clinical signs, cultures (TYM, TYI-S-33, dorset, and horse serum), and molecular approaches such as polymerase chain reaction, which is the most sensitive and specific method for the detection of $T$. vaginalis ${ }^{[14-16]}$. The 
appropriate treatment for trichomoniasis includes the 5'-nitroimidazole derivatives of which metronidazole and tinidazole are the only efficient FDA approved drugs. Recently, some other drugs have been introduced for the treatment of this disease (Table 1) ${ }^{[17-29]}$. Besides, simultaneous treatment of both sexual partners (female and male) is recommended ${ }^{[17-}$ 20]. Treatment efficiency depends on the influence of host factors. Nitroimidazole may also be required for the effective treatment of HIV-infected women who are infected with $T$. vaginalis. Drug resistance to metronidazole has been reported in some cases ${ }^{[30,31]}$. In recent years, many attempts have been made for the evaluation of the effects of plants on different microorganisms that cause vaginal infection on $T$. vaginalis in vaginal infection. Nowadays, many studies have been performed in replacing medicinal plants with synthetic drugs ${ }^{[32-36]}$.

Search of electronic databases and journals was performed to find the related data reporting the in vitro effects of various plant extracts on $T$. vaginalis in Iran. The international databases, including PubMed, Scirus, ISI Web of Science, Scopus, EMBASE, Science Direct, and Google Scholar, as well as national databases covering Iran Medex, IranDoc, Magiran, and Scientific Information Database (ISC) were searched. These searches limited to articles published between the years 2006 and 2016. The keywords used for the literature search for this review were "Trichomonas vaginalis", "medicinal plants", "herbal drug", "plant extract", "anti-trichomonas activity", "in vitro", and "Iran".

\section{Chemical drugs for treatment of trichomoniasis}

\section{Metronidazole}

Metronidazole is a member of the nitroimidazole family and prevents genetic material synthesis by disrupting the DNA of microrganism cells. Metronidazole is highly active against anaerobic bacteria and anaerobic parasites including $T$. vaginalis $^{[30,37]}$. The pharmacological properties of this drug are suitable, and it is accessible as oral, intravenous, vaginal, and topical forms. After oral administration, it is well absorbed and reached the highest level within 1 to 2 hours after ingestion ${ }^{[30,37,38]}$. This drug is effective against many anaerobic bacteria and parasites. Urinary tract is the prominent way of metronidazole excretion. Anaerobic infections, such as abdominal infections, genital tract infections, septicemia, endocardial infection, bone infections, brain and spinal cord infections, pulmonary infections, cutaneous infections. Before some surgeries, metronidazole is used to prevent secondary infections ${ }^{[30,37,38]}$

Side effects and the problem of metronidazole resistance

Side effects in systemic metronidazole therapy (in less than $1 \%$ of patients) include vomiting, diarrhea, abdominal cramps, headache, drowsiness and fever. Intravenous administration is typically associated with thrombophlebitis. Infrequent side effects consists mouth ulcers, headache, glossitis, dizziness, inflammation of the mouth and lips and dark-colored

Table 1. Chemotherapeutic agents against trichomoniasis

\begin{tabular}{llc}
\hline Drug name & Medial use & Ref. \\
\hline Metronidazole & Anti-protozoan (giardiasis, trichomoniasis, and amebiasis) & {$[17-20]$} \\
Tinidazole & Anti-protozoan (amebiasis, giardiasis, and trichomonasis) & {$[21,22]$} \\
Secnidazole & Anti-protozoan (trichomonasis and dientamoebiasis) & {$[21,29]$} \\
Ornidazole & Anti-protozoan (trichomoniasis) & {$[23]$} \\
Nimorazole & Anti-protozoan (trichomoniasis and head and neck cancer) & {$[24]$} \\
Nitrothiazole & Anti-protozoan (giardiasis, trichomoniasis, and amebiasis) & ${ }^{[25]}$ \\
Nitazoxanide & Anti-protozoan (cryptosporidiosis, giardiasis, hymenolepiasis, ascariasis, and resistant Trichomoniasis) & {$[26,25]$} \\
Hamycin & Anti-protozoan (trichomoniasis) & {$[27]$} \\
Paramomycin & Cutaneous leishmaniasis, visceral leishmaniasis, and anti-recurrent $T$. vaginalis & {$[28]$} \\
Sodium nitrite & Anti-microbial and anti- $T$. vaginalis resistance to metronidazole (used in traditional medicine) & {$[29]$} \\
Nitrofuran & Antimicrobials and anti-T. vaginalis & {$[29]$} \\
Furazolidone & Antibacterial and anti-T. vaginalis & {$[29]$} \\
\hline
\end{tabular}

Ref., references 
urine $^{[17-29,39]}$. Irregular and long-term use of the metronidazole has led to drug resistance, which is the most important reason for the treatment failure ${ }^{[37]}$. If there is suspicion of metronidazole resistance, metronidazole susceptibility assay is required as it can help to determine the course of subsequent treatment ${ }^{[29,40]}$. The increase in the prevalence of metronidazole-resistant strains shows a need for development of non-nitroimidazole drugs to combat resistant trichomoniasis. Recently, some studies have been conducted to introduce new drugs against trichomoniasis. The use of herbal medicines has been considered due to fewer side effects. While the synthetic drugs are obtained from non-renewable sources as petrochemicals materials, medicinal plants, are renewable in nature ${ }^{[30-36,41]}$

\section{Tinidazole}

Tinidazole is antiparasitic drug from the 5-nitro- imidazole family. This drug is commonly used for treating $T$. vaginalis in America. Compared to metronidazole, tinidazole has longer half-life, higher tissue distribution, and fewer side effects. However, its mechanism of action is similar to metronidazole, and the occurrence of cross-resistance is possible. Studies have shown an incomplete cross-resistance to tinidazole in metronidazole-resistant isolates that can possibly be treated by tinidazole, but the similarity of metabolic pathways in metronidazole and tinidazole causes the rapid spread of resistance to tinidazole. Also, its cost is more than metronidazole; therefore, it cannot be used commonly ${ }^{[22,42]}$.

\section{Literature review of herbal medicine for treatment of trichomoniasis}

Active ingredients of plant extract against $T$. vaginalis are mentioned in Table 2.

Table 2. Active ingredients of plant extracts against $T$. vaginalis in Iran (2006-2016)

\begin{tabular}{|c|c|c|}
\hline Botanical name & Active ingredients & Part used \\
\hline Artemisia aucheri Boiss. & $\operatorname{Artemisinin}^{[43,51]}$ & Leaves \\
\hline Zataria multifora Boiss. & Thymol $^{[44-47,51]}$ & Leaves \\
\hline Myrtus communis & Cineol, tannins, and flavonoids ${ }^{[48-51]}$ & Leaves \\
\hline Allium sativum (garlic) & $\begin{array}{l}\text { Organosulfur compound, Allicin, Diallyl disulphide, S-Allyl cysteine, } \\
\text { and Diallyl trisulfide }{ }^{[52,53,56]}\end{array}$ & Whole plant \\
\hline Ferula assa-foetida & Monoterpenoids ${ }^{[54-56]}$ & Whole plant \\
\hline Lavandula angyustifolia & $\begin{array}{l}\text { Linalool alcohol, Cineol, Camohor, Sterzoaldehyde ketone, and } \\
\text { lavandulol }{ }^{[57-59]}\end{array}$ & Leaves and flowers \\
\hline Eucalyptus camaldulensis & Terpenoid and phenolic compound ${ }^{[60,61]}$ & Leaves \\
\hline Stachys sylvatica & $\alpha$-Pinene, $\beta$-Pinene, germacrene-D, and flavonoids ${ }^{[62,63]}$ & Aerial parts \\
\hline Achillea millefolium & Flavonoids ${ }^{[64,67]}$ & whole plant and leaves \\
\hline Artemisia absinthium & $\begin{array}{l}\text { Monoterpene (thujone), absinthen, azulenes, phenolic compounds, } \\
\text { Flavonoids }{ }^{[66,67]}\end{array}$ & Leaves \\
\hline Juglans regia & Tannin and naphthoquinones ${ }^{[65,67]}$ & Leaves and twigs \\
\hline Tanacetum Parthenium & Tancin, lactones, and terpenes ${ }^{[68,69]}$ & Leaves \\
\hline Taxus baccata & Alkaloids (taxines $\mathrm{A}$ and $\mathrm{B})^{[70,71]}$ & Leaves \\
\hline Viola odorata & Phenolic, terpenoid, and alkaloid compounds ${ }^{[72,73]}$ & Leaves, flowers, and stems \\
\hline Pelarqonium roseum & Geranium, citronellol, mannitol, and ethyl alcohol ${ }^{[74,75]}$ & Leaves, flowers, and roots \\
\hline Verbascum thapsus & $\begin{array}{l}\text { Saponins, glycosides, glycosoaminoglycans, phenyl ethanol, and } \\
\text { verbascose }^{[76,77]}\end{array}$ & Leaves, flowers, and stems \\
\hline Allium Cера & $\begin{array}{l}\text { Organosulfur compounds, Allyl sulfides, flavonoids, and } \\
\text { flavenols }\end{array}$ & Whole plant \\
\hline Oliveria Decumbens Vent & Tymol, threpenin, and carvacrol ${ }^{[79]}$ & Aerial parts \\
\hline Muscari neglectum & Flavonoid, alkaloid, terpenoid, and steroid ${ }^{[80,81]}$ & Flowers \\
\hline
\end{tabular}




\section{Artemisia aucheri Boiss, Zataria multifora Boiss, and Myrtus communis}

These plants are native in Iran and are used in traditional medicine as antiparasitic drugs. Artemisia aucheri Boiss contains artemisinin, which has antiparasitic properties ${ }^{[43]}$, and Zataria multifora Boiss contains the high amount of thymol, which has antiinflammatory, antiseptic and antibacterial effects ${ }^{[44-47]}$. Myrtus communis is composed of cineol, tannins and flavonoids, which have antiseptic, antioxidant, antibacterial, antiviral and antifungal activities ${ }^{[48-50]}$. Ziaiye et $a l^{[51]}$ surveyed the effect of alcoholic extract of these three plants on $T$. vaginalis in vitro. Their results showed that these extracts have different chemical compositions and special effects that inhibit the growth of $T$. vaginalis. Also, all of them had maximum effect in $0.1 \% \mathrm{w} / \mathrm{v}$ and 4 hours after culture so that after this time no parasites were found alive.

\section{Garlic and Ferula assa-foetida}

Allium sativum, is the scientific name of garlic, belongs to onion genus. Garlic is native to Central Asia and has been used over than 7000 years. Garlic is used as anticoagulant, anticommon cold, anti cancer and antiparasite ${ }^{[52,53]}$. Ferula assa-foetida is native to the deserts of Iran and mountains of Afghanistan and is commonly cultivated in nearby India. This plant grows in different provinces of Iran such as Khorasan, Sistan and Baluchestan, Kerman, and Fars. Ferula assafoetida is used as a digestion aid, antimicrobial, abortifacient, antidote for opium, remedy for asthma and bronchitis, and fighting influenza ${ }^{[54,55]}$. Sarkari et al. ${ }^{[56]}$ studied the effect of garlic and Ferula assafoetida extract on the growth and proliferation of $T$. vaginalis. Based on the results of this study, $90 \%$ of the parasites were killed one hour after adding Ferula assa-foetida extract at the concentration of $2 \mathrm{mg} / \mathrm{ml}$, but only $5 \%$ of the parasites survived after 2 hours by adding garlic extract at concentration of $0.1 \mathrm{mg} / \mathrm{ml}$.

\section{Lavandula angyustifolia}

Lavandula belongs to family Lamiceae and genus Lavanduleae. This plant has traditional application as a sedative as well as an antispasmodic, antiparasitic, antibacterial, antioxidant, anticancer, antivirus, antidepressants and anti-inflammatory remedy ${ }^{[57,58]}$. Investigation of antitrichomonal activity of Lavandula angyustifolia essential oil in vitro was conducted by Ezatpur et al. ${ }^{[59]}$. They showed that all concentrations of lavender essential oil have good antitrichomonal effect and reduce the number of parasites; all the parasites were killed 90 minutes after exposure to $0.1 \%$ Lavandula angyustifolia essential oil.

\section{Eucalyptus camaldulensis}

Various biological effects of eucalyptus, including antibacterial, antihyperglycemic, and antioxidant activities have been reported, and it seems that the essential oils of Eucalyptus, containing terpenoid and phenolic compounds, play a major role in its biological activities $^{[60]}$. Effects of various concentration of Eucalyptus camaldulensis extracts on $T$. vaginalis parasite in culture medium have been surveyed by Hassani et al. ${ }^{[61]}$. The obtained results indicated that $E$. camaldulensis extract had $80 \%$ growth inhibition in a concentration of $12.5 \mathrm{mg} / \mathrm{ml}$ after $24 \mathrm{~h}$. Alcoholic extract in a concentration of $25 \mathrm{mg} / \mathrm{ml}$ showed $100 \%$ growth inhibition after $24 \mathrm{~h}$, and ethyl acetate extract had $100 \%$ growth inhibition with the minimum concentration of $12.5 \mathrm{mg} / \mathrm{ml} 24 \mathrm{~h}$ after culture. Eventually, water extract in the concentration of 50 $\mathrm{mg} / \mathrm{ml}$ indicated $80 \%$ and $100 \%$ growth inhibition after 48 and $72 \mathrm{~h}$, respectively ${ }^{[61]}$.

\section{Stachys sylvatica}

Stachys is one of the largest genera in the Lamiaceae plant family. It is a genus of about 300 species and a subfamily of Lamioideae. The distribution of the genus covers Europe, Asia, Africa, Australasia, and North America. This plant grows in different regions of Iran's provinces such as Isfahan, Chaharmahal and Bakhtiari, and Lorestan. In traditional medicine, this herb is considered as anti-pain, anti-neuralgia, antioxidant, antipyretic, and appetizer ${ }^{[62]}$. Sereshti et al. ${ }^{[63]}$ investigated the effect of aqueous and alcoholic extracts of the plant Stachys sylvatica on T. vaginalis in vitro. Their results indicated that aqueous and alcoholic extracts of the plant after 72 hours in medium culture TYI-S-33 had no effect on T. vaginalis, and metronidazole was more effective than this extract ${ }^{[63]}$.

\section{Achillea millefolium, Juglans regia, and Artemisia absinthium}

Achillea millefolium is a flowering plant in the family Asteraceae. It is native to the temperate regions of the Northern Hemisphere in Asia, Europe, and North America. This plant has anti-inflammatory, antispasmodic and antioxidant activities ${ }^{[64]}$. Juglans regia belongs to the Juglandaceae family and Juglans genus and has tannin and naphthoquinones with potent bactericidal effects. The extract of this tree is used to treat headaches, colds, skin diseases, as well as fungal, bacterial and viral infections ${ }^{[65]}$. Artemisia absinthium belongs to the Asteraceae family and genus of Artemisia. This plant has medicinal properties, including insecticide and appetizer, as well as bactericidal, anti-inflammatory and antiparasitic effects $^{[66]}$. The leaves extracts of Achillea millefolium, Artemisia absinthium, and Juglans regia on $T$. 
vaginalis was studied by Khalili et al. ${ }^{[67]}$ in vitro. All three plant extracts represented anti-trichomoniasis activity after 24 hour and parasites immobility increased. However, six hours after cultivation with Achillea millefolium, Artemisia absinthium, and Juglans regia extracts at the concentrations of 800 , 400 , and $800 \mathrm{mg} / \mathrm{ml}$, respectively, all parasites were $\operatorname{died}^{[67]}$.

\section{Tanacetum parthenium}

Tanacetum parthenium (local name: fever few) belongs to Asteraceae family and is a native plant in Iran $^{[68,69]}$. Tanacetum parthenium, as a traditional medicinal herb, is commonly used to prevent migraine headaches and has been used as a herbal treatment to reduce fever, arthritis, and digestive problems ${ }^{[68,69]}$. Its main compound is tannin, and others compounds include lactones (parthenolide and canine) and terpenes ${ }^{[68,69]}$. Study of the effect of hydro-alcoholic extract of Tanacetum Parthenium on T. vaginalis was conducted by Arefkhah et al. ${ }^{[69]}$. Alcoholic extract of this plant with concentrations of $4,5,8$, and $10 \mathrm{mg} / \mathrm{ml}$ showed the same lethal effect on the parasite as compared to metronidazole, but concentrations of 1 and 1.25 indicated no effect ${ }^{[69]}$.

\section{Taxus baccata}

Taxus baccata is a conifer native to Western, Central and Southern Europe, as well as Northwestern Africa, Northern Iran, and Southwestern Asia ${ }^{[0,71]}$. This traditional medicine plant has antibacterial, antifungal, anti-inflammatory and antitumoral activities and is used for treating malaria, rheumatism, bronchitis, and asthma $^{[70,71]}$. In 2013, Zarea et al. ${ }^{[71]}$ investigated the effects of Taxus baccata leaves fractions on $T$. vaginalis growth in culture medium. The component of $60 \%$ of crude extract at concentrations of 200, 300, 400 , and $500 \mu \mathrm{g} / \mathrm{ml}$ indicated higher anti-T. vaginalis effects than $90 \%(P<0.05)$. Concentration of $200 \mu \mathrm{g} / \mathrm{ml}$ of the extract of $60 \%$ caused $100 \%$ inhibition, but the component of $90 \%$ indicated $60 \%$ growth inhibition ${ }^{[71]}$.

\section{Viola odorata}

Viola odorata is a species of the genus Viola that is native to Europe and Asia and has been introduced to North America and Australia. In herbal medicine, $V$. odorata has been used for treating a variety of respiratory ailments, insomnia, and skin disorders ${ }^{[72,73]}$. Its compounds include phenolics, violin, and glycosides. In the leaves of this plant, analgesic components are salicylic acid glycosides ${ }^{[72,73]}$. The effects of different extracts of Viola odorata on $T$. vaginalis in culture medium has investigated by Salehi et $a l .{ }^{[73]}$. The crude extract of leave $(4 \mathrm{mg} / \mathrm{ml})$, flower
(4 $\mathrm{mg} / \mathrm{ml})$, and root $(2 \mathrm{mg} / \mathrm{ml})$ of Viola odorata showed $100 \%$ growth inhibition after 24 hours $^{[73]}$.

\section{Pelarqonium roseum}

Pelarqonium roseum belongs to the Geraniaceae family and Pelargonium genus. The major compounds of this plant are geranium, citronellol, mannitol, and ethyl alcohol ${ }^{[74,75]}$. It is used in traditional medicine as analgesic, anti-dysentery, and disinfectants as well as an anti-inflammatory, a hemostatic, and an antiseptic $\operatorname{drug}^{[74,75]}$. Fakhrie-Kashan et al. $^{[75]}$ studied the effects of aqueous and alcoholic extracts of Pelarqonium roseum on the growth of $T$. vaginalis in vitro. IC50s (inhibitory concentration, 50\%) of aqueous and alcoholic extracts of Pelarqonium roseum on the growth of $T$. vaginalis after $24 \mathrm{~h}$ were 54.67 and 27.63 $\mu \mathrm{g} / \mathrm{ml}$, respectively ${ }^{[75]}$.

\section{Verbascum thapsus}

Verbascum thapsus is a member of scorphulariaceae family. This biennial plant grows in a wide range of areas and can be two meters or more in height ${ }^{[76,77]}$. Verbascum thapsus contains bioactive substances such as saponins, glycosides, glycosoaminoglycans, phenyl ethanol, and verbascose ${ }^{[76,77]}$ and also chemical components that reduce cyclooxygenase activity. These components have anti-inflammatory activity and germicide and skin restore effects ${ }^{[76,77]}$. Verbascum thapsus has also been used to treat genital and urinary tract infections and diarrhea ${ }^{[76,77]}$. Induction of apoptosis in $T$. vaginalis due to the extract of this plant have been reported by Kashan et al. ${ }^{[77]}$. IC50s (inhibitory concentration, $50 \%$ ) of ethanolic extract of Verbascum thapsus and metronidazole after $24 \mathrm{~h}$ were 39.17 and $0.0326 \mu \mathrm{g} / \mathrm{ml}$, respectively. Results of this study indicated that the percentage of apoptosis after treatment of parasites with various concentrations of Verbascum thapsus extract $(25,50,100,200$, and 400 $\mu \mathrm{g} / \mathrm{ml}$ ) were $20.7,37.04,47.5,62.72$, and 86.35 respectively $^{[77]}$.

\section{Allium cepa, Oliveria decumbens Vent, and Muscari neglectum}

The onion is a vegetable and the most widely cultivated species of the genus Allium. This plant grows in most parts of the world and Iran flora. It is used in traditional medicine for treatment of diseases of kidney, bladder, and prostate ${ }^{[78]}$. Oliveria decumbens Vent belongs to Umbeliferae family and grows in Southern Iran. It is bactericide and contains tymol, threpenin, and carvacrol ${ }^{[79]}$. Museari negleetum is native to the Mediterranean region ${ }^{[80,81]}$. In 2015, Fakhrieh-Kashan et al. ${ }^{[81]}$ investigated the in vitro therapeutic effect of alcoholic extracts Allium cepa, 
Oliveria decumbens Vent, and Muscari neglectum against $T$. vaginalis. In this study, IC50s of Allium cepa, Oliveria decumbens Vent, and Muscari neglectum ethanol extracts after $24 \mathrm{~h}$ were 572.3, 101.8 , and $329.4 \mu \mathrm{g} / \mathrm{ml}$, respectively ${ }^{[81]}$.

In conclusion, trichomoniasis is considered as one of the most common sexually transmitted diseases in humans ${ }^{[1,2]}$. Increasing resistance to drugs such as metronidazole leads to a serious problem; thus, new effective tactics are needed to treat this infection. The current medications and the first-line drugs for treatment of trichomoniasis are metronidazole and tinidazole; both are 5-nitroimidazole drugs approved by the US FDA. Besides, using metronidazole is limited because of its high toxicity, high doses, and development of drug resistance ${ }^{[30,37-39]}$. In order to improve the treatment of $T$. vaginalis infection, natural products could be a source of new drugs with low toxicity and high activity. Recently, many efforts have been made for the evaluation of the effects of plants on the pathogenic microorganisms that can lead to vaginal infection. Due to the diversity of Iranian medicinal plants, several studies have carried out on the $T$. vaginalis using these herbs. Unfortunately, previous studies have not used an identical procedure; therefore, we cannot exactly explain which plant extracts are more effective on the parasite. However, we can draw the conclusion that all plants with the largest effect on the parasites contain the following active compounds: cineol, tannins, flavonoid, terpenoid, phenolic ones, Artemisia, lactones, glycosides, geranium, citronium, mannitol, saponins, glycosoaminoglycans, verbascose, phenyl ethanol, tymol, threpenin, carvacrol, zingerone, paradol, gingerols, shogaols, inulin, polyacetylene, arctic aside. Until now, no herbal extract has been introduced as an approved drug for the treatment of trichomoniasis. More accurate and comprehensive studies are needed to achieve the desired results in the use of plants in trichomoniasis treatment.

\section{CONFLICT OF INTEREST. None declared}

\section{REFERENCES}

1. Harp DF, Chowdhury I. Trichomoniasis: evaluation to execution. European journal of obstetrics and gynecology and reproductive biology 2011; 157(1): 3-9.

2. Sutton M, Sternberg M, Koumans EH, McQuillan G, Berman S, Markowitz L. The prevalence of Trichomonas vaginalis infection among reproductiveage women in the United States, 2001-2004. Clinical infectious diseases 2007; 45(10): 1319-1326.

3. Tobin W. Alfred Donné and Léon Foucault: the first applications of electricity and photography to medical illustration. Journal of visual communication in medicine 2006; 29(1): 6-13.

4. Nijhawan AE, Chapin KC, Salloway R, Andrea S. Prevalence and predictors of trichomonas infection in newly incarcerated Women. Sexually transmitted diseases 2012; 39(12): 973-978.

5. Mao M, Liu HL. Genetic diversity of Trichomonas vaginalis clinical isolates from Henan province in central China. Pathogens and global health 2015; 109(5): 242-246.

6. Dirkx M, Boyer MP, Pradhan P, Brittingham A, Wilson WA. Expression and characterization of a $\beta$ fructofuranosidase from the parasitic protist Trichomonas. BMC biochemistry 2014; 15: 12.

7. World Health Organization, Dept. of Reproductive Health and Research. REterieved from: http://www.who.int/reproductivehealth/about_us/en/.

8. Sharafi SM, Yousefi M, Yousefi HA, Asghari G, Darani $\mathrm{HY}$. In vitro effects of various plants extracts on the growth of Trichomonas vaginalis. Infectious disorders drug targets 2013; 13(5): 322-327.

9. Sariego I, Monzote L, Rojas L. Setting a colorimetric assay with MTT for assessment of trichomonicidal activity. Current clinical pharmacology 2014; 9(3): 283-287.

10. Sutton M, Sternberg M, Koumans EH, McQuillan G, Berman S, Markowitz L. The prevalence of Trichomonas vaginalis infection among reproductiveage women in the United States, 2001-2004. Clinical infectious diseases 2007; 45(10): 1319-1326.

11. Sena AC, Miller WC, Hobbs MM, Schwebke JR, Leone PA, Swygard H, Atashili J, Cohen MS. Trichomonas vaginalis infection in male sexual partners: implications for diagnosis, treatment, and prevention. Clinical infectious diseases 2007; 44(1): 13-22.

12. Manshoori A, Mirzaei S, Valadkhani Z, Kazemi Arababadi M, Rezaeian M, Zainodini N, Bahramabadi R, Zare-Bidaki M. A diagnostic and symptomatological study on trichomoniasis in symptomatic pregnant women in Rafsanjan, South Central Iran in 2012-13. Iranian journal of parasitology 2015; 10(3): 490-497.

13. Secor WE, Meites E, Starr MC, Workowski KA. Neglected parasitic infections in the United States: trichomoniasis. American journal of tropical medicine and hygiene 2014; 90(5): 800-804.

14. Camila BM, Mariana dos SM, Tiana TASCA. Comparsion of permanent staining methods for the laboratory diagnosis of trichomoniasis. Revista do instituto de medicina tropical de são Paulo 2016; 58: 5.

15. Mahmoud A, Sherif NA, Abdella R, El-Genedy AR, El Kateb AY, Askalani AN. Prevalence of Trichomonas vaginalis infection among Egyptian women using culture and Latex agglutination: cross-sectional study. BMC womens health 2015; 15: 7.

16. Khatoon R, Jahan N, Ahmad S, Khan HM, Rabbani T. Comparison of four diagnostic techniques for detection of Trichomonas vaginalis infection in females attending tertiary care hospital of North India. Indian journal of pathology and microbiology 2015; 58(1): 36-39.

17. Ali V, Nozaki T. Current therapeutics, their problems, 
and sulfur-containing-amino-acid metabolism as a novel target against infections by "amitochondriate" protozoan parasites. Clinical microbiology reviews 2007; 20(1): 164-187.

18. Forbes GL Drayton R, Forbes GD. A case of metronidzole-resistant Trichomonas vaginalis in pregnancy. International journal of STD and AIDS 2016; 27(10): 906-908.

19. Hawkins I, Carne C, Sonnex C, Carmichael A. Successful treatment of refractory Trichomonas vaginalis infection using intravenous metronidazole. International journal of STD and AIDS 2015; 26(9): 676-678.

20. Meites E, Gaydos CA, Hobbs MM, Kissinger P, Nyirjesy P, Schwebke JR, Secor WE, Sobel JD, Workowski KA. A review of evidence-based care of symptomatic trichomoniasis and asymptomatic Trichomonas vaginalis infections. Clinical infectious diseases 2015; 61(8): 837-848.

21. Kauser H, Qadir M, Anwar W. Ocular side effect of tinidazole: A rare case report. Journal of family medicine and primary care 2014; 3(4): 467-469.

22. Gretchenl LJ. Tinidazole (Tindamax) for Trichomonas and bacterial vaginosis. American family physician 2009; 79(2): 102-105.

23. Thulkar J, Kriplani A, Agarwal N. A comparative study of oral single dose of metronidazole, tinidazole, secnidazole and ornidazole in bacterial vaginosis. Indian journal of pharmacology 2012; 44(2): 243-245.

24. McCann JS, Horner T, Shepherd I, Quin N. 2-day treatment of trichomoniasis with nimorazole. The British journal of venereal diseases 1974; 50(5): 375376.

25. Fox LM, Saravolatz LD. Saravolatz. Nitazoxanide: a new thiazolide antiparasitic agent. Clinical infectious diseases 2005; 40(8): 1173-1180.

26. Dan M, Sobel JD. Failure of nitazoxanide to cure trichomoniasis in three women. Sexually transmitted diseases 2007; 34(10): 813-814.

27. Lushbaugh WB,Cleary JD, Finley RW. Cytotoxicity of hamycin for Trichomonas vaginalis, HeLa and BHK-21. The journal of antimicrobial chemotherapy 1995; 36(5): 795-780.

28. Tayal SC, Ochogwu SA, Bunce H. Paromomycin treatment of recalcitrant Trichomonas vaginalis. International journal of STD and AIDS 2010; 21(3): 217-218

29. Cudmore SL, Delgaty KL, Hayward-McClelland SF, Petrin DP, Garber GE. Treatment of infections caused by metronidazole-resistant Trichomonas vaginalis: clinical microbiology reviews 2004; 17(4): 783-793.

30. Löfmark S, Edlund C, Nord CE. Metronidazole is still the drug of choice for treatment of anaerobic infections. Clinical infectious diseases 2010; 50(Suppl1): S16-S23.

31. Land KM, Johnson PJ. Molecular basis of metronidazole resistance in pathogenic bacteria and protozoa. Drug Resistance Updates 1999; 2(5): 289-294.

32. Vermani K, Garg S. Herbal medicines for sexually transmitted disease and AIDS. Journal of ethnopharmacology 2002; 80(1); 49-66.
33. Ezz Eldin HM, Badawy AF. In vitro anti-trichomonas vaginalis activity of Pistacia lentiscus mastic and Ocimum basilicum essential oil. Journal of parasitic disease 2015; 39(3): 465-473.

34. El-Sherbiny GM, El Sherbiny ET. The Effect of Commiphora molmol (Myrrh) in treatment of Trichomoniasis vaginalis infection. Iranian Red Crescent medical journal 2011; 13(7): 480-486.

35. Yan Y, Gao XZ. Protein analysis of Trichomonas vaginalis treated by Pulsatilla chinensis in vitro. Zhongguo ji sheng chong xue yu ji sheng chong bing za zhi 2010; 28(3): 231-233.

36. Ertabaklar H, Kivçak $\mathrm{B}$, Mert $\mathrm{T}$, Ozensoy Töz S. In vitro activity of Arbutus unedo leaf extracts against Trichomonas vaginalis trophozoites. Turkiye parazitolojii dergisi 2009; 33(4): 263-265.

37. Narcisi EM, Secor WE. In vitro effect of tinidazole and furazolidone on metronidazole-resistant Trichomonas vaginalis. Antimicrobial agents and chemotherapy 1996; 40(5): 1121-1125.

38. Sherrard J, Ison C, Moody J, Wainwright E, Wilson J, Sullivan A. United Kingdom national guideline on the management of Trichomonas vaginali 2014. International journal of STD and AIDS 2014; 25(8): 123-137.

39. Sarma GR, Kamath V. Acute painful peripheral neuropathy due to metronidazole. Neurology India 2005; 53(3): 372-273.

40. Schwebke JR, Barrientes FJ. Prevalence of Trichomonas vaginalis isolates with resistance to metronidazole and tinidazole. Antimicrobial agents chemotherapy 2006; 50(12): 4209-4210.

41. Semnani MK, Saeidi M, Mahdavi MR, Rahimi F. Antimicrobial effects of methanolic extracts of some species of stachys and phlomis. Journal of Mazandaran university of medical sciences. 2007; 17(57): 57-66.

42. Forbes GL, Drayton R, Forbes GD. A case of metronidazole-resistant Trichomonas vaginalis in pregnancy. International journal of STD and AIDS 2015; 27(10): 906-908.

43. Hashemi P, Abolghasemi MM, Fakhari AR, Ebrahimi SN, Ahmadi S. Hydrodistillation-solvent microextraction and GC-MS identification of volatile components of Artemisia aucheri. Chromatographia 2007; 66(3-4): 283-286.

44. Zomorodian K, Saharkhiz MJ, Rahimi MJ, Bandegi A, Shekarkhar G, Bandegani A, Pakshir K, Bazargani A. Chemical composition and antimicrobial activity of the essential oil of Zataria multiflora. Pharmacognosy magazine 2006; 19(2): 52-59.

45. Saleem M, Nazli R, Afza N, Sami A, Ali MS. Biological significance of essential oil of Zataria multiflora Boiss. Natural products research 2004; 18(6): 493-497.

46. Abbasgholizadeh N, Ettehad GH, Arab R, Nemati A, Barak M, Pirzadeh A, Zarei M. Antibacterial effects of Zataria multiflora Boiss. (Shiraz oregano essence) on Enterobacteriaceae species. Research journal of biological sciences 2008; 3(3): 345-347.

47. Ettehad GH, Arab R. Evaluation of antibacterial effects of Shiraz oregano essence (Zataria multiflora Boiss) on 
Salmonella typhi and comparing to antibiotics. Research journal of biological sciences 2007; 2(6): 674-676.

48. Burt S. Essential oils: their antibacterial properties and potential applications infoods-a review. International journal of food microbiology 2004; 94(3): 223-253.

49. Chryssavgi G, Vassiliki P, Athanasios M, Kibouris T, Michael K. Essential oil compo-sition of Pistacia lentiscus L. and Myrtus communis L.: evaluation of antioxidant capacity of methanolic extracts. Food chemistry 2008; 107(3):1120-1130.

50. Kalemba D, Kunicka A. Antibacterial and antifungal properties of essential oils. Current medicinal chemistry 2003; 10(10): 213-229.

51. Ziaiye H, Azadbakht M, Abdollahi F, Shabankhani B. Effect of methanolic extracts of Artemisia aucheri Boiss., Zataria multiflora Boiss. and Myrtus communis L. on Trichomonas vaginalis (in vitro). Journal of Gorgan university of medical sciences 2006, 8(1): 3438.

52. Benkeblia N. Antimicrobial activity of essential oil extracts of variousonions (Allium cepa) and garlic (Allium sativum). LWT-food science and technology 2004; 37(2): 263-268.

53. Mikaili P, Maadirad S, Moloudizargari M, Aghajanshakeri S, Sarahroodi S. Therapeutic uses and pharmacological properties of Garlic, Shallot, and their biologically active compounds. Iranian journal of basic medical sciences 2013; 16(10): 1031-1048.

54. Lee CL, Chiang LC, Cheng LH, Liaw CC, Abd ElRazek MH, Chang FR, Wu YC. Influenza A (H1N1) antiviral and cytotoxic agents from Ferula assafoetida. Journal of natural products 2009; 72(9): 1568-1572.

55. Mahendra P, Bisht Sh. Ferula asafoetida: Traditional uses and pharmacological activity. Pharmacognosy reviews 2012; 6(12): 141-146.

56. Bahadoor Sarkari, Hadisa Tadayon, Shahrbanoo Askarian, Elahm Farnia, Mehrangiz Askarian. In vitro anti-Trichomonas activity of Freula assafoetida and garlic extract. Journal of Gorgan university of medical sciences $2009 ; \mathbf{1 1}(3)$ : 13-17.

57. Danh LT, Han NL, Triet NDA, Zhao J, Mammucari R, Foster N. Comparison of chemical composition, antioxidant and antimicrobial activity of lavender (Lavandula angustifolia L.) essential oils extracted by supercritical $\mathrm{CO}_{2}$, hexane and hydrodistillation. Food and bioprocess technology 2012; 6(12): 3481-3489.

58. Jianu C, Pop G, T Gruia A, Horhat FG. Chemical composition and antimicrobial activity of essential oils of lavender (Lavandula angustifolia) and lavandin (Lavandula $x$ intermedia) grown in Western Romania. International journal of agriculture and biology 2013; 15(4): 772-776.

59. Ezatpur B, Badparva E, Ahmadi Sh, Rashidipur M, Ziaiye H. Investigation of anti Trichomonas vaginalis activity of Lavandula angyustifolia essential oil in invitro media. Journal of Ilam university of medical sciences 2009; 16 (4): 31-38.

60. Huang HC, Ho YC, Lim JM, Chang TY, Ho CL, Chang TM. Investigation of the anti-melanogenic and antioxidant characteristics of Eucalyptus camaldulensis flower essential oil and determination of its chemical composition. International journal of molecular sciences 2015; 16(5): 10470-10490.

61. Hassani S, Asghari Gh, Yousefi H, Kazemian A, Rafieiean M, Yousofi Darani H. Effects of different extracts of Eucalyptus camaldulensis on Trichomonas vaginalis parasite in culture medium. Advanced biomedical research 2013; 2: 47.

62. Hajdari A, Novak J, Mustafa B, Franz C. Essential oil composition and antioxidant activity of Stachys sylvatica L. (Lamiaceae) from different wild populations in Kosovo. Natural product research 2012; 26(18): 1676-1681.

63. Sereshti M, Yousofi Darani H, Zebardast N, Rafean M, Manochehre Naeini K, Yousofi HA. Effect of ethanolic and watery extract of aerial parts of Stachys Lavandulifolia on Trichomonas vaginalis, in vitro. Journal of medicinal plants 2012; 1(41): 159-165.

64. Kotan R, Cakir A, Dadasoglu F, Aydin T, Cakmakci R, Ozer H, Kordali S, Mete E, Dikbas N. Antibacterial activities of essential oils and extracts of Turkish Achillea, Satureja and Thymus species against plant pathogenic bacteria. Journal of the science of food and agriculture 2010; 190(1): 145-160.

65. Yang H, Sung SH, Kim YC. The ethanolic extract of Juglans sinensis leaves and twigs attenuates CCl4induced hepatic oxidative stress in rats. Pharmacognosy magazine 2015; 11(43): 533-539.

66. Jasna MC, Sonja MD, Gordana SC, Vesna TT. Freeradical scavenging activity of wormwood (Artemisia absinthium) extracts. Journal of the science of food and agriculture 2004; 85(2): 265-272.

67. Khalili B, Rafieian M, Hejazi SH, Yusefi HA, Yektaian N, Shirani-Bidabadi L. Effect of Achillea millefolium, Artemisia absinthium and Juglans regia leaves extracts on Trichomonas vaginalis, in vitro. Journal of Shahrekord university of medical sciences 2011; 12(4): 62-69.

68. Rabito MF, Britta EA, Pelegrini BL, Scariot DB, Almeida MB, Nixdorf SL, Nakamura CV, Ferreira IC. In vitro and in vivo antileishmania activity of sesquiterpene lactone-rich dichloromethane fraction obtained from Tanacetum parthenium (L.) Schultz-Bip. Experimental parasitology 2014; 143: 18-23.

69. Arefkhah N, Taghipur S, Yousefi M, Rafeiean M, Daneshpur S, Yousefi H. In-vitro effect of hydroalcoholic extract of tanacetum parthenium extract on Trichomonas vaginalis. Journal of Isfahan medical school 2013; 31(236): 623-629.

70. Bernhoft A. Bioactive Compounds in Plants-Benefits and Risks for Man and Animals. Oslo: The Norwegian Academy of Science and Letters, 2010.

71. Zarea A, Asghari GHR, Ghanadian M, Yousefi HA, Yousofi Darani H. Effect of Taxus baccata leaves fractions on Trichomonas vaginalis growth in culture medium. Armaghane danesh 2014; 18(11): 888-899.

72. Siddiqi HS, Mehmood MH, Rehman NU, Gilani AH. Studies on the antihypertensive and antidyslipidemic activities of Viola odorata leaves extract. Lipids in health and disease 2012; 11: 6. 
73. Salehi L, Asghari Gh, Yousofi H, Yousofi Darani H. Effects of different extracts of Viola odorata on Trichomonas vaginalis in culture medium. Journal of Isfahan medical school 2014; 31(266): 2139-2148.

74. Edris AE. Pharmaceutical and therapeutic potentials of essential oils and their in dividual volatile constituents: a review. Phytotherapy research 2007; 21(4): 308-323.

75. Fakhrie-Kashan Z, Arbabi M, Delavari M, Taghi-Zadeh M, Hooshyar H, Solaymani F. The effect of aqueous and alcoholic extracts of Pelarqonium roseum on the growth of Trichomonas vaginalis in vitro. Feyz 2014; 18(4): 369-375.

76. Riaz M, Zia-Ul-Haq M, Jaafar, HZE Jaafar. Common mullein, pharmacological and chemical aspects. Revista brasileira de farmacognosia 2013; 23(6): 948-959.

77. Kashan ZF, Arbabi M, Delavari M, Hooshyar H, Taghizadeh M, Joneydy Z. Effect of Verbascum thapsus ethanol extract on induction of apoptosis in Trichomonas vaginalis in vitro. Infectious disorders- drug targets 2015; 15(2): 125-130.

78. Mantawy MM, Ali HF, Rizk MZ. Therapeutic effects of Allium sativum and Allium cepa in Schistosoma mansoni experimental infection. Revista do instituto de medicina tropical de são paulo 2011: 53(3): 155-163.

79. Motamedi H, Darabpour E, Gholipour M, Nezhad SM. Antibacterial effect of ethanolic and methanolic extracts of Plantago ovate and Oliveria decumbens endemic in Iran against some pathogenic bacteria. International journal of pharmacology 2010; 6(2): 117-122.

80. Nasrabadi M, Halimi M, Nadaf M. Phytochemical screening and chemical composition of extract of Muscari neglectum. Middle-East journal of scientific research 2013; 14(4): 566-569.

81. Fakhrieh-Kashan Z, Arbabi M, Delavari M, Hooshyar $\mathrm{H}$, Taghizadeh $\mathrm{M}$. therapeutic effect of Allium cepa, Oliveria decumbens Vent and Muscari neglectum against Trichomonas vaginalis, In vitro. Journal of research in medical sciences 2015; 32(310): 1985-1992. 